\title{
In silico identification of compounds from Nigella sativa seed oil as potential inhibitors of SARS-CoV-2 targets
}

\author{
Chidi Edbert Duru ${ }^{1 *} \mathbb{D}$, ljeoma Akunna Duru² and Abayomi Emmanuel Adegboyega ${ }^{3,4}$
}

\begin{abstract}
Background: The growing number of cases, severity and fatality of the COVID-19 pandemic, coupled with the fact that no cure has been found has made infected individuals especially in Africa, to resort to the consumption of different natural products to alleviate their condition. One of such plant materials that have been consumed to remedy the severity of this viral infection is the oil of Nigella sativa seed commonly called black seed oil. In this study, we extracted and characterized the oil from this seed using gas chromatography coupled to a mass selective detector to identify the component phytochemicals. Site-directed multiligand docking of the identified compounds was performed on SARS-CoV-2 molecular targets- Replicase polyprotein 1a, RNA binding protein of NSP9, ADP ribose phosphatase of NSP3, 3-chymotrypsin-like protease 3CLpro, and RNA-dependent RNA polymerase RDRP, and ACE2-angiotensinconverting enzyme from the Homo sapiens.

Results: The binding affinity of caryophyllene oxide was the highest on 3CLpro $(-6.0 \mathrm{kcal} / \mathrm{mol}), \mathrm{NSP} 3(-6.3 \mathrm{kcal} /$ $\mathrm{mol})$, NSP9 $(-6.3 \mathrm{kcal} / \mathrm{mol})$, and RDRP $(-6.9 \mathrm{kcal} / \mathrm{mol})$ targets, while a-bergamotene gave the best binding affinity on RPIA (5.7 kcal/mol) target. The binding affinity of $\beta$-bisabolene on the ACE2 target $(-8.0 \mathrm{kcal} / \mathrm{mol}$ ) was almost the same as Remdesivir $(-8.1 \mathrm{kcal} / \mathrm{mol})$. The ADMET properties of these three phytochemicals showed that they are good drug leads for these SARS-CoV-2 receptors.

Conclusion: The findings from this study strongly indicate that the reported recovery from COVID-19 infection claimed by patients who consumed black seed oil could be linked to the presence of caryophyllene oxide, a-bergamotene, and $\beta$-bisabolene in this natural product.
\end{abstract}

Keywords: Nigella sativa, Angiotensin-converting enzyme, SARS-CoV-2, $\beta$-bisabolene, Binding affinity

\section{Background}

Black cumin, scientifically known as Nigella sativa L., is an annual dicotyledonous herb that belongs to the family Ranunculaceae (Datta et al. 2012). It is a small shrub ranging between 20 and $90 \mathrm{~cm}$ in height, with tapering green leaves and rosaceous pink, purple, white, yellow, or pale blue flowers with 5-10 petals. Flowering starts in July and the seeds ripen in September. The ripe fruit

\footnotetext{
*Correspondence: chidiedbertduru@gmail.com

${ }^{1}$ Surface Chemistry and Environmental Technology (SCENT) Research Unit, Department of Chemistry, Imo State University, Owerri, Imo State, Nigeria

Full list of author information is available at the end of the article
}

is a capsule with 3-7 united follicles containing numerous tiny, pitch-black seeds with an aromatic and slightly bitter taste (Ahmad et al. 2013). It is native to northeastern Africa, the eastern Mediterranean, and southwestern Asia (Vavilov and Dorofeev 1992). The species is grown in many countries like India, Turkey, Middle East, Pakistan, Syria, and Saudi Arabia (Naz 2011). The seeds of $N$. sativa have been widely used as diuretics, anti-diarrheal, analgesic, antibacterial, antidiabetic, anticancer, immunomodulator, anti-inflammatory, spasmolytic, bronchodilator, hepatoprotective, renal protective, gastro-protective, antioxidant, etc. (Ahmed et al. 2013; Sultan et al. 2014). 
The chemical composition of seed extracts of N. sativa seed varies from one country to another and also from one region in a country to another (Shariq et al. 2015). The major components in $N$. sativa seed are fatty oils and aliphatic hydrocarbons, arachidonic acid, tocopherols, $\gamma$-linolenic acid, and essential oil, which contains carvacrol, $\rho$-cymene, thymoquinone, $\alpha$-pinene, and indazole-type alkaloids, isoquinoline alkaloids, as well as dolabellane-type diterpene alkaloids. The food and therapeutic applications of $N$. sativa oil and seed have a long history in many cultures. Islamic medicine also cataloged the numerous benefits of this plant (Sharma et al. 2009). Its compounds have been shown to have various pharmacological effects on different body parts. Empirical studies have reported that the seed oil and seed extracts have antimicrobial activities, which some workers have attributed to the presence of compounds such as thymohydroquinone and melanin (Kalim 2013; Al Yahya 1986). The seed extract contains numerous antioxidants like carvacrol, $\mathrm{t}$-anethole, and 4-terpineol, and their activities have been reported in different studies (Awadalla 2012). Also, available reports have shown the anti-inflammatory, anticancer, anti-diabetic, and hepatoprotective activities of its oil and extracts (Umar et al. 2012; Peng et al. 2013; Abdelmeguid et al. 2010).

The Coronavirus disease 2019 (COVID-19) caused by the severe acute respiratory syndrome Coronavirus 2 (SARS-CoV-2) began in Wuhan, China, and was reported to the World Health Organization on December 31, 2019 (WHO 2020). The pandemic ravaged the entire globe, claiming hundreds of thousands of lives. Community to community transmission is now evident in many countries, with a daily rise in the number of cases. There are potential drug targets essential for the survival of the coronavirus, which include a 3-chymotrypsin-like protease (3CLpro), Angiotensin-converting enzyme (ACE2), ADP ribose phosphatase of Nonstructured Protein 3 (NSP3), Nonstructured Protein 9 RNA binding protein (NSP9), RNA-dependent RNA polymerase (RdRp), and Replicase Polyprotein 1a (RP1a). To infect the host, the structural spike glycoprotein interacts with the transmembrane protein of the human host cell receptor ACE2 (Guy et al. 2005). The main protease 3CLpro acts in the viral polyprotein large Replicase Polyprotein 1a (RP1a) proteolytic cleavage, cleaving it into functional units to produce nonstructural viral constituents like RdRp, NSP3, and NSP9. This makes 3CLpro and ACE2 important drug targets to inhibit Nonstructured Proteins production and terminate viral action. The RP1a and the NSPs (RdRp, NSP3, and NSP9) are important targets involved in the replication and translation process, which lead to a viral proliferation in host cells (Kumar et al. 2020). In vitro and in silico studies of possible cures for this dreaded disease have become hot topics in current research. Although no drug is currently available to cure this disease, Remdesivir, an antiviral drug has been clinically tested and confirmed useable in the interim (Williamson et al. 2020).

Recently, the governor of Oyo State in Nigeria revealed that the oil from $N$. sativa seed was one of the remedies he consumed to combat the disease, a week after he tested positive for COVID-19 (Punch Newspaper, April 7,2020 ). So far, no attempt has been made to investigate the veracity of this claim. In this study, the oil from the seed of $N$. sativa was extracted, and the identified phytochemical components docked on some selected SARS$\mathrm{CoV}-2$ proteins. The dock scores of these compounds were compared to the values obtained with a standard COVID-19 prescription drug.

\section{Methods}

\section{Sample collection and preparation}

Mature seeds of $N$. sativa were collected toward the end of rainy season in October 2020 (average temperature $29{ }^{\circ} \mathrm{C}$ ), from a fallow farmland in Northern Nigeria (N $10^{\circ} 9^{\prime} 32.2524 "$, E $\left.8^{\circ} 8^{\prime} 1.8816^{\prime \prime}\right)$, and no permissions or licenses were required for the collection and study. They were identified by a professional taxonomist Prof. F.N. Mbagwu of the Department of Plant Science and Biotechnology, Imo State University, Owerri, Nigeria, and the voucher specimen was deposited at the Imo State University Herbarium, with herbarium number IMSUH468. They were washed with tap water and left to dry on a laminated paper for one week under room conditions. The dried seeds were subjected to preliminary grinding using mortar and pestle, and the particle size was further reduced using an electric blender. The seed powder was transferred in an airtight plastic container and stored in a refrigerator at $4{ }^{\circ} \mathrm{C}$.

\section{Extraction of oil}

Oil was extracted from the ground seed powder using a Soxhlet apparatus mounted on a heating mantle (Duru 2020). The seed powder of weight $100 \mathrm{~g}$ was encapsulated in a clean white cotton cloth previously degreased in hexane ( $\geq 98.5 \%$, Sigma-Aldrich, Darmstadt, Germany). The sample was held in the thimble-holder of the extractor which was gradually filled with condensed redistilled hexane from a distillation flask placed on a heating mantle. When the solvent reaches the overflow level in the thimble-holder, it is siphoned back into the distillation flask, carrying the extracted oil with it. The operation was repeated until complete extraction was achieved. The extracted oil was then recovered from the solvent by rotary evaporation. 


\section{Characterization of oil}

The oil sample was characterized using gas chromatography-mass Spectrometer (GC-MS) instrument (Model: $7890 \mathrm{GC}$ and 5977B MSD, Agilent Technologies, USA). An HP-5 MS capillary standard nonpolar column $\mathrm{L} \times \mathrm{I}$.D., $30 \mathrm{~m} \times 0.25 \mathrm{~mm}$ and film thickness $0.25 \mu \mathrm{m}$ was used. The flow rate of mobile phase (carrier gas: $\mathrm{He}$ ) was set at $1.0 \mathrm{~mL} / \mathrm{min}$. In the gas chromatography part, the temperature program (oven temperature) was set at $40{ }^{\circ} \mathrm{C}$ and raised to $250{ }^{\circ} \mathrm{C}$ at $5{ }^{\circ} \mathrm{C} / \mathrm{min}$ and injection volume 1 $\mu \mathrm{L}$. The oil sample was dissolved in methanol $(\geq 99.8 \%$, Sigma-Aldrich, Darmstadt, Germany) and fully scanned at a range of $40-650 \mathrm{~m} / \mathrm{z}$, and the results were compared using NIST mass spectral library search program (ElSawi et al. 2020).

\section{Identification and preparation of ligands}

The 3D structure-data files (SDF) of the compounds in the crude oil sample were identified and downloaded from the PubChem database. They were minimized in
PyRx virtual screening tool, using Universal Force Field at 200 steps. They were then converted to AutoDock ligands (pdbqt) and used for the docking analysis.

\section{Identification and preparation of molecular targets}

Five SARS-CoV-2 molecular targets (Fig. 1), Replicase polyprotein 1a (6YHU), RNA binding protein of NSP9 (6W4B), ADP ribose phosphatase of NSP3 (6VXS), 3-chymotrypsin-like protease 3CLpro (6LU7) and RNAdependent RNA polymerase RDRP (7BTF), and one protein of host, ACE2-Angiotensin-converting enzyme (6LZG), were identified from literature (Konkolova et al. 2020; Tan et al. 2020; Michalska et al. 2020; Jin et al. 2020; Gao et al. 2020; Wang et al. 2020) and downloaded from the Protein Data Bank (PDB). The interfering crystallographic water molecules and cocrystallized ligand were removed, and minimization of the energy of the protein was then done using UCSF Chimera 1.14 (Pettersen 2004; Duru et al. 2020). The protein was minimized at 300 steepest descent steps at $0.02 \AA$. The conjugate gradient

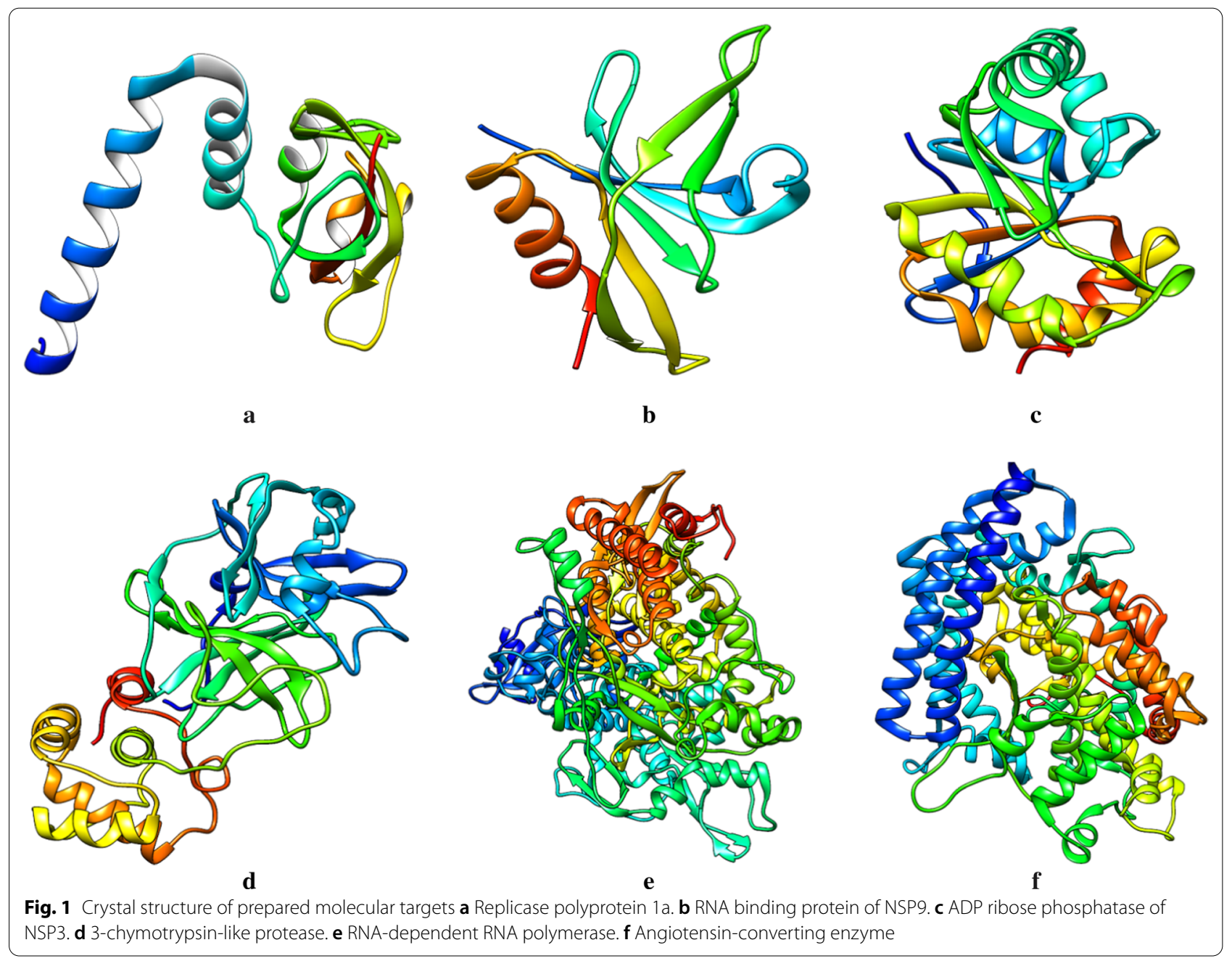


steps were 10 at $0.02 \AA$ and 10 update intervals. Gasteiger charges were added using Dock Prep to get a good structure conformation.

\section{Determination of active sites on SARS-CoV-2 proteins}

The active sites of the proteins were determined using CASTp (Computed Atlas for Surface Topography of Proteins).

(Tian et al. 2018; http://sts.bioe.uic.edu/castp/index .html?j_5f45dd381f58d).

\section{Docking procedure and analysis of results}

The screening of the phytochemical compounds from the oil was performed by docking them on selected binding pockets of SARS-CoV-2 proteins and ranked based on their binding energies. The multiple docking of the ligands and proteins was done with Autodock Vina in PyRx software (Tsao et al. 2020; Johnson et al. 2020). The molecular docking results were organized on an Excel spreadsheet, and the Heat Map of the data was viewed using the Conditional Formatting function.

\section{Absorption, distribution, metabolism and elimination and toxicity (ADMET) analysis}

The compounds with the lowest binding energy for each protein were selected and submitted to the ADMETsar 2 server to examine their drug-like properties, pharmacokinetics, and pharmacodynamics parameters (Yang et al. 2019).

\section{Analysis of protein-ligand interactions}

The interactions between the most potent compounds in the oil and amino acid residues of the proteins were visualized using Biovia Discovery studio client 20.1 (BIOVIA 2020) and UCSF Chimera software.

\section{Results}

\section{Chemical composition of oil extract}

The GC-MS analysis of N. sativa seed oil gave 27 peaks for the compounds detected, and the chromatogram is shown in Fig. 2.

The elution information of the compounds and their therapeutic uses are summarized in Table 1.

The phytochemical components were present in the order linoleic acid $>$ palmitic acid $>$ methyl linoleate $>$ D-limonene $>2$,4-decadienal, (E,E)-> (Z)-hept-2enal $>$ m-cymene $>2$-decenal, $\quad(\mathrm{E})$ - $>$ 9,17-octadecadienal, (Z)- $>$ methyl palmitate $>\beta$-pinene $>1,2$-dimethylcyclopentan-1-ol $=$ myristic $\quad$ acid $>\alpha$-bergamotene $=\beta$-bisabolene $>\alpha$-pinene $>$ trans-4-methoxy thujane $>1$-cynaopyrolidine $>$ terpineol $>\alpha$-thujene $=\gamma$-terpinene $>1,3$-dimethylcyclohexanol $>$ caryophyllene oxide $>$ thymoquinone $>$ tetradecane $>$ geranyl-2-methylb-

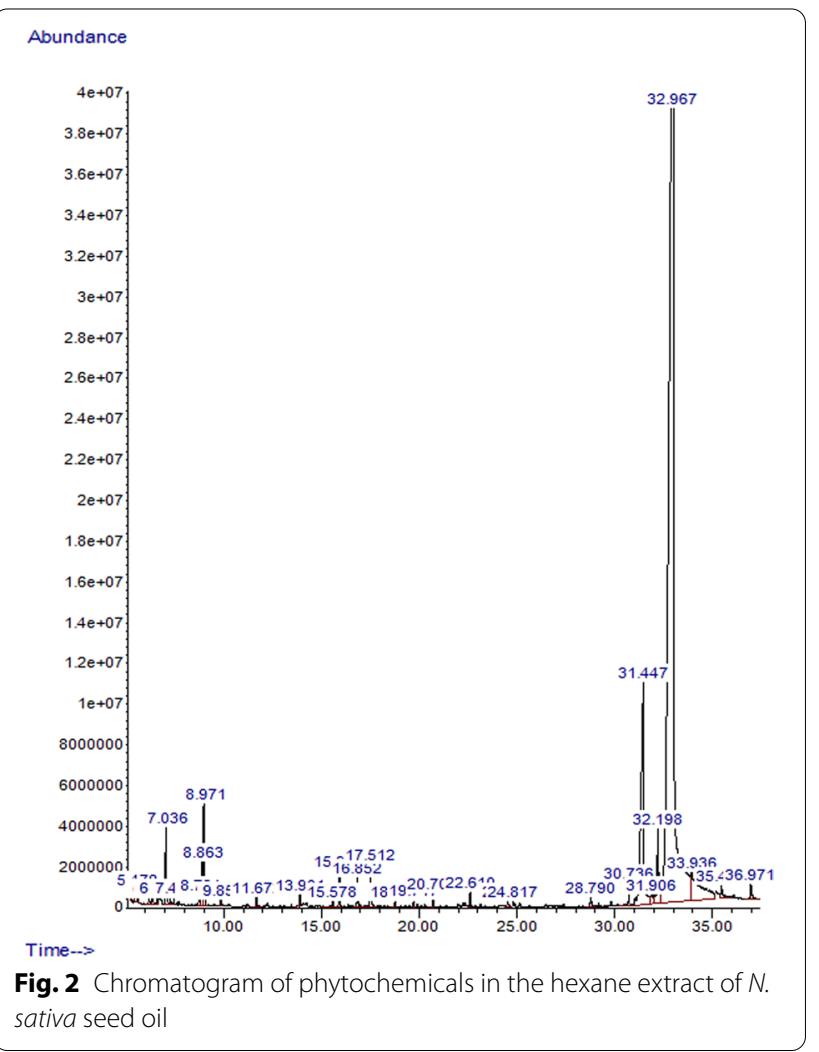

utyrate $>$ hexadecane (Fig. 3). About $90 \%$ of the entire oil was comprised of linoleic acid (79.61\%) and palmitic acid (10\%).

The binding affinities of the compounds from the oil extract to the SARS-CoV-2 receptors are shown in Table 2.

\section{Discussion}

Most of the identified phytochemicals in $N$. sativa seed oil have previously been reported to show antidiabetic, anti-inflammatory, antioxidant, anticancer, antimicrobial, anti-arthritic, anticonvulsant, antiulcer, antihypertensive, anti-nociceptive, hepatoprotective, cytotoxic, antimycomicrobial, antiparasitic, and analgesic activities (Marques et al. 2019; Caboni et al. 2012; Begum et al. 2016; Lang and Buchbauer 2012; Balamurugan et al. 2013; Muniyan and Gurunathan 2016; Saeed et al. 2012; Zhao et al. 2018; Adeoye-Isijola et al. 2018; Wu et al. 2017; Chavan et al. 2009; Yimer et al. 2019; Hadi et al. 2016; Engels and Brinkmann 2017). These compounds showed varying degrees of binding on the SARS-CoV-2 protein targets (Table 2), as revealed by the change in Gibb's free energy values $(\Delta G)$ (Duru and Duru 2020). The FDA emergency approved drug Remdesivir (Williamson et al. 2020), administered on adults and children with suspected or confirmed cases of COVID-19, 
Table 1 Phytochemical compounds identified in N. sativa seed oil

\begin{tabular}{|c|c|c|c|c|}
\hline Peak & $\%$ wt & Name of compound & PubMed CID & Therapeutic uses \\
\hline 1 & 0.22 & 1,2-dimethylcyclopentan-1-ol & 551296 & Still unknown \\
\hline 2 & 0.14 & a-thujene & 17868 & Anti-inflammatory; anti-arthritic; antimicrobial \\
\hline 3 & 0.19 & a-pinene & 6654 & Anti-inflammatory; antioxidant; anticancer; antimicrobial \\
\hline 4 & 0.13 & 1,3-dimethylcyclohexanol & 558957 & Still unknown \\
\hline 5 & 1.30 & (Z)-hept-2-enal & 5362616 & Still unknown \\
\hline 6 & 0.23 & $\beta$-pinene & 14896 & Antimicrobial \\
\hline 7 & 0.17 & 1-cynaopyrrolidine & 73737 & Still unknown \\
\hline 8 & 0.63 & m-cymene & 10812 & Anti-inflammatory \\
\hline 9 & 1.61 & D-Limonene & 440917 & Anti-inflammatory; anticancer; antimicrobial \\
\hline 10 & 0.14 & $\gamma$-Terpinene & 7461 & Anti-inflammatory; antioxidant; antimicrobial \\
\hline 11 & 0.18 & Trans-4-methoxy thujane & - & Antimicrobial \\
\hline 12 & 0.15 & Terpineol & 17100 & $\begin{array}{l}\text { Antioxidant; anticancer; anticonvulsant; antiulcer; anti- } \\
\text { hypertensive; anti-nociceptive }\end{array}$ \\
\hline 13 & 0.11 & Thymoquinone & 10281 & $\begin{array}{l}\text { Anti-inflammatory; hepatoprotective; antioxidant; } \\
\text { anticancer; cytotoxic }\end{array}$ \\
\hline 14 & 0.52 & 2-decenal, (E)- & 5283345 & Antinematicidal \\
\hline 15 & 1.39 & 2,4-decadienal, (E,E)- & 5283349 & Antinematicidal \\
\hline 16 & 0.08 & Geranyl-2-methylbutyrate & 6437648 & Still unknown \\
\hline 17 & 0.09 & Tetradecane & 12389 & Antimicrobial \\
\hline 18 & 0.20 & a-bergamotene & 86608 & Antimicrobial \\
\hline 19 & 0.20 & $\beta$-bisabolene & 10104370 & Antimicrobial; Anti-ulcer \\
\hline 20 & 0.12 & Caryophyllene oxide & 1742210 & Anti-inflammatory; antimicrobial; antiparasitic; analgesic \\
\hline 21 & 0.06 & Hexadecane & 11006 & Antibacterial \\
\hline 22 & 0.22 & Myristic acid & 11005 & Antimycomicrobial \\
\hline 23 & 0.25 & Methyl palmitate & 8181 & Anti-inflammatory \\
\hline 24 & 10.00 & Palmitic acid & 985 & Antioxidant; antibacterial; anti-inflammatory; antitumor \\
\hline 25 & 1.62 & Methyl linoleate & 5284421 & Antioxidant \\
\hline 26 & 79.61 & Linoleic acid & 5280450 & Antidiabetic \\
\hline 27 & 0.44 & 9,17-Octadecadienal, (Z)- & 5365667 & Anti-inflammatory; antioxidant \\
\hline
\end{tabular}

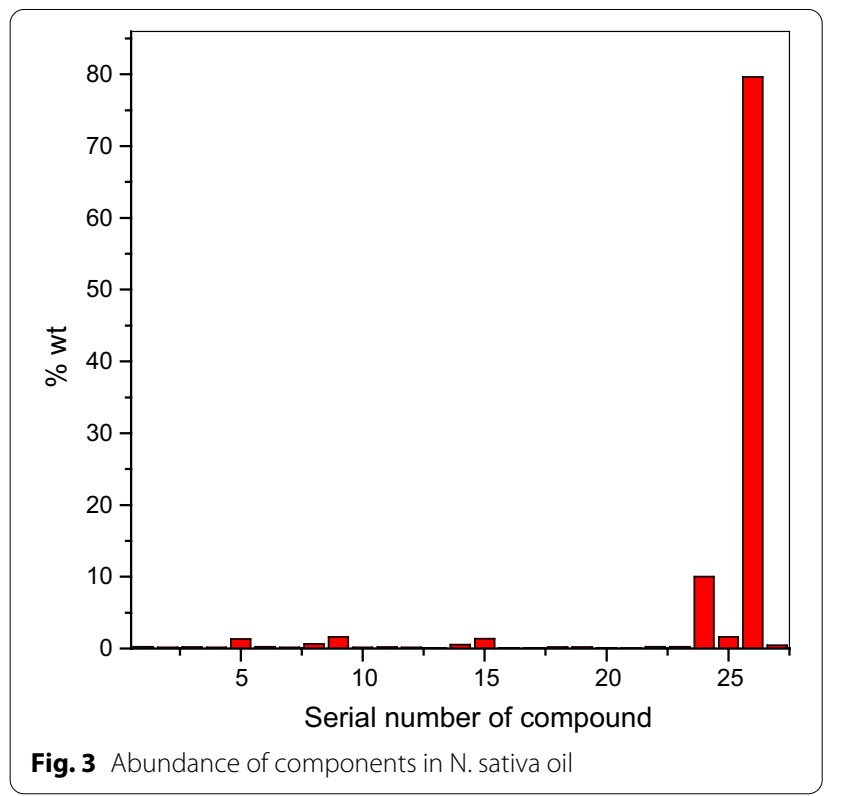

was used as a control to identify compounds with good binding affinities for the studied COVID-19 proteins. Caryophyllene oxide had the best binding affinities on 3CLpro $(-6.0 \mathrm{kcal} / \mathrm{mol})$, NSP3 $(-6.3 \mathrm{kcal} / \mathrm{mol})$, NSP9 $(-6.3 \mathrm{kcal} / \mathrm{mol})$, and RDRP $(-6.9 \mathrm{kcal} / \mathrm{mol})$ targets. The compound $\alpha$-bergamotene gave the best binding affinity on RPIA $(5.7 \mathrm{kcal} / \mathrm{mol})$, while $\beta$-bisabolene displayed an excellent binding affinity on the ACE2 protein target. These values were very close to those obtained using the antiviral control drug. The binding affinity of $\beta$-bisabolene $(-8.0 \mathrm{kcal} / \mathrm{mol})$ was almost similar to Remdesivir $(-8.1 \mathrm{kcal} / \mathrm{mol})$ on the ACE2 target. This observation is an indication that $\beta$-bisabolene could prevent the interaction of the spike glycoprotein of the virus with the ACE2 protein of the human host cell, thereby preventing infection of the host.

The structures of the compounds with the highest docking scores for the studied proteins are shown in Fig. 4. The absorption, distribution, metabolism, 
Table 2 Binding affinities of compounds in the oil of N. sativa seed for SARS-CoV-2 proteins

\begin{tabular}{|c|c|c|c|c|c|c|}
\hline Compound & \multicolumn{6}{|c|}{$\Delta G$ Energy (Kcal/mol) } \\
\hline \multirow{3}{*}{$\begin{array}{l}\text { 1,2-dimethylcyclopentan-1-ol } \\
\alpha \text {-thujene }\end{array}$} & 3CLpro & ACE2 & NSP3 & NSP9 & RDRP & RP1A \\
\hline & -4.2 & -5.0 & -3.9 & -4.2 & -4.5 & -3.5 \\
\hline & -4.7 & -6.6 & -4.8 & -5.0 & -5.8 & -4.4 \\
\hline$\alpha$-pinene & -4.7 & -5.2 & -4.8 & -4.7 & -5.8 & -4.4 \\
\hline 1,3-dimethylcyclohexanol & -4.5 & -5.0 & -4.4 & -4.4 & -5.1 & -3.8 \\
\hline (Z)-hept-2-enal & -3.8 & -5.0 & -3.8 & -4.0 & -4.3 & -3.4 \\
\hline$\beta$-pinene & -4.8 & -5.2 & -4.8 & -4.7 & -5.7 & -4.4 \\
\hline 1-cynaopyrrolidine & -3.8 & -4.7 & -3.4 & -3.4 & -4.3 & -3.0 \\
\hline m-cymene & -5.0 & -6.9 & -4.9 & -5.4 & -5.8 & -4.8 \\
\hline D-Limonene & -5.0 & -6.8 & -4.8 & -5.1 & -5.6 & -4.6 \\
\hline$\gamma$-Terpinene & -5.0 & -7.0 & -4.7 & -5.2 & -5.7 & -4.9 \\
\hline Trans-4-methoxy thujane & -5.0 & -5.4 & -4.9 & -5.0 & -5.3 & -4.4 \\
\hline Terpineol & -5.3 & -6.8 & -5.1 & -5.3 & -6.2 & -4.7 \\
\hline Thymoquinone & -4.9 & -7.0 & -5.2 & -5 & -5.7 & -5.0 \\
\hline 2-decenal, (E)- & -3.7 & -5.6 & -4.2 & -4.2 & -4.5 & -4.0 \\
\hline 2,4-decadienal, (E,E)- & -4.2 & -5.7 & -4.5 & -4.8 & -5.0 & -4.2 \\
\hline Geranyl-2-methylbutyrate & -5.1 & -6.4 & -5.7 & -5.3 & -5.6 & -5.1 \\
\hline Tetradecane & -3.8 & -5.7 & -4.2 & -4.1 & -4.2 & -4.3 \\
\hline$\alpha$-bergamotene & -5.4 & -6.2 & -6.1 & -5.7 & -6.2 & -5.7 \\
\hline$\beta$-bisabolene & -5.5 & -8.0 & -5.7 & -6.2 & -6.0 & -5.1 \\
\hline Caryophyllene oxide & -6.0 & -5.9 & -6.3 & -6.3 & -6.9 & -5.5 \\
\hline Hexadecane & -3.9 & -4.7 & -4.4 & -4.0 & -4.6 & -3.8 \\
\hline Myristic acid & -4.6 & -4.9 & -4.6 & -4.5 & -5.1 & -4.2 \\
\hline Methyl palmitate & -3.8 & -5.1 & -4.9 & -5.0 & -4.9 & -4.6 \\
\hline Palmitic acid & -4.4 & -5.2 & -4.7 & -4.4 & -5.1 & -4.2 \\
\hline Methyl linoleate & -4.2 & -4.9 & -4.7 & -5.4 & -5.3 & -4.8 \\
\hline Linoleic acid & -5.0 & -5.7 & -5.2 & -4.9 & -5.5 & -5.1 \\
\hline 9,17-Octadecadienal, (Z)- & -4.2 & -6.0 & -4.6 & -4.3 & -4.8 & -4.2 \\
\hline Remdesivir (Control drug) & -7.8 & -8.1 & -7.2 & -6.8 & -8.0 & -6.0 \\
\hline
\end{tabular}

excretion, and toxicity (ADMET) properties which show their pharmacokinetics and pharmacodynamics properties are summarized in Table 3. Lipinski's rule of five, which is determined by a complex balance of various molecular properties and structural features such as lipophilicity, electronic distribution, hydrogen bonding 

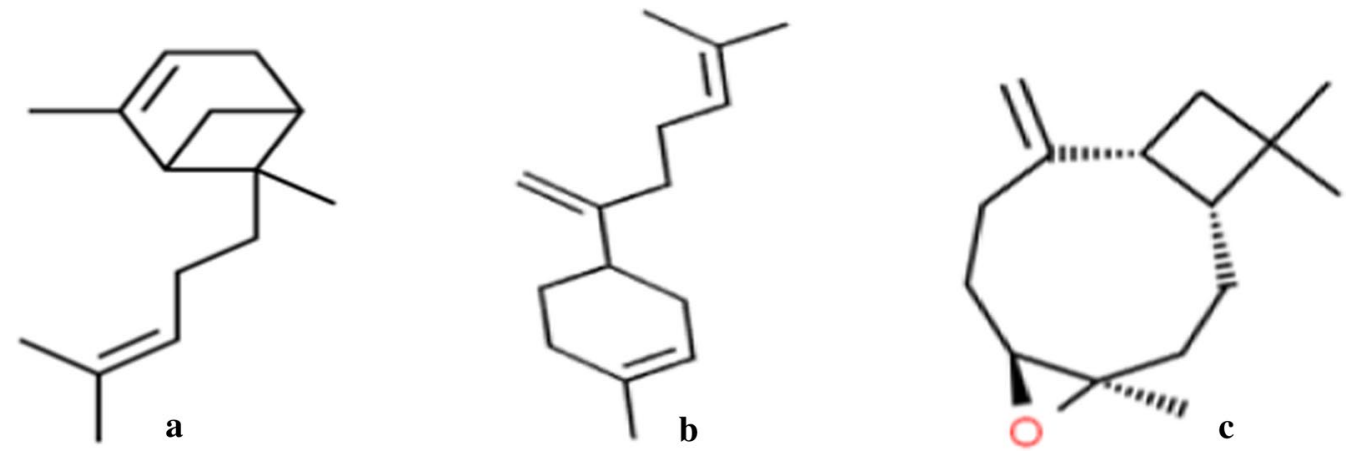

Fig. 4 Structures of $\mathbf{a}$ a-bergamotene, $\mathbf{b} \beta$-bisabolene, $\mathbf{c}$ Caryophyllene oxide

Table 3 ADMET properties of a-bergamotene, $\beta$-bisabolene, and Caryophyllene oxide relative to Remdesivir

\begin{tabular}{|c|c|c|c|c|}
\hline ADMET properties & a-bergamotene & $\beta$-bisabolene & Caryophyllene oxide & Remdesivir \\
\hline Molecular weight & 204.36 & 204.36 & 220.36 & 602.56 \\
\hline WlogP & 4.7 & 5.0 & 3.9 & 2.2 \\
\hline H-bond acceptor & 0 & 0 & 1 & 13 \\
\hline H-bond donor & 0 & 0 & 0 & 4 \\
\hline Rotatable bonds & 3 & 3 & 0 & 13 \\
\hline Blood-brain barrier & + & + & + & + \\
\hline Carcinogenicity (binary) & - & - & - & - \\
\hline Human intestinal absorption & + & + & + & + \\
\hline Acute oral toxicity & 2.32 & 2.05 & 2.24 & 3.43 \\
\hline Water solubility & -4.97 & -4.89 & -3.45 & -4.12 \\
\hline
\end{tabular}

characteristics, molecule size, and flexibility, as well as the presence of various pharmacophores that influence the behavior of a molecule in a living organism, were used to predict the drug likeliness of the compounds. A good drug candidate should not violate more than one of the rules (Lipinski 2016).

The molecular weights of the compounds were $<500$, and their hydrophobicity $(\log \mathrm{P})$ did not exceed 5 . The hydrogen bond donor ( $\leq 5$ hydrogens) and hydrogen bond acceptor (not more than 10 hydrogens) of the compounds were in line with the rule. The rotatable bonds (not more than 3) were in line with the rule of three, and their acute oral toxicity values were well below $5 \mathrm{mg} / \mathrm{kg}$. Caryophyllene oxide is soluble in water, while $\alpha$-bergamotene and $\beta$-bisabolene are moderately soluble. The human intestinal adsorption and blood-brain barrier of the compounds were very high, and the compounds were not carcinogenic. These results are indications that $\alpha$-bergamotene, $\beta$-bisabolene, and caryophyllene oxide are excellent drug candidates (Zhong 2017).

The 3D and 2D protein-ligand interaction images for $\alpha$-bergamotene, $\beta$-bisabolene, and caryophyllene oxide are shown in Fig. 5. The amino acid residues involved in the interactions with the compounds and the control drug Remdesivir are depicted in Table 4.

The hydrogen bond, pi-sigma, pi-alkyl, and alkyl type interactions were the main forces that held the compounds in the protein pockets. At least two hydrogen bonds were observed in all the protein-Remdesivir interactions, and one was found only in the RDRP-caryophyllene oxide interaction. The protein-Remdesivir interactions in all the protein pockets had at least two hydrogen bonds and the other interacting forces, in the pockets of the studied proteins. Caryophyllene oxide and Remdesivir interacted with ASN 209 by hydrogen bonding in RDRP, while $\alpha$-bergamotene and Remdesivir interacted by alkyl forces with ILE 120, ALA 150, and ALA 102. These suggested that the mechanism of inhibition of the proteins at these sites by caryophyllene oxide and $\alpha$-bergamotene was similar to the action of Remdesivir at those sites.

\section{Conclusions}

The phytochemical composition and binding affinity of compounds in the oil extract from Nigella sativa seed on SARS-CoV-2 molecular targets were investigated. The 

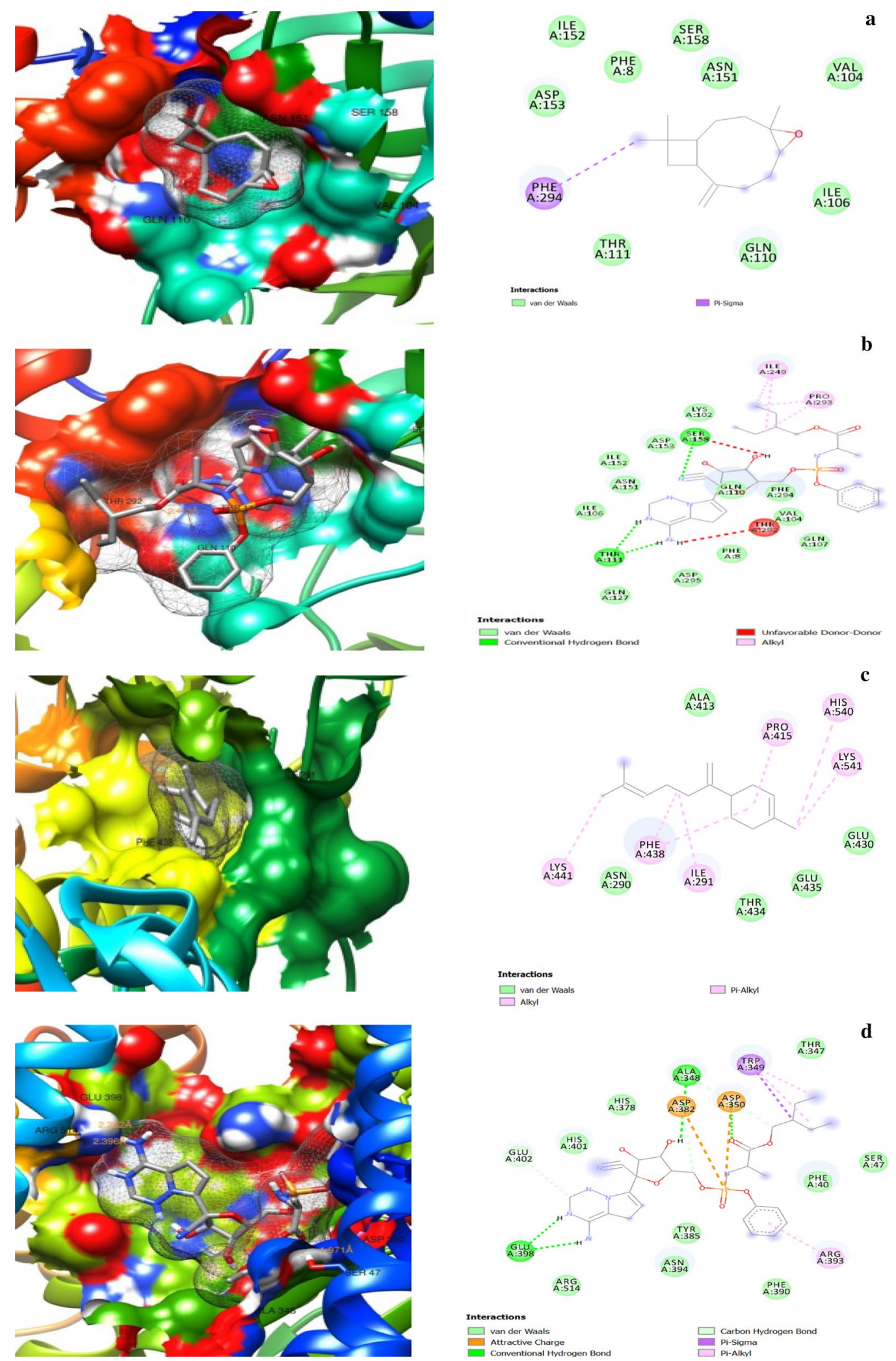

Fig. 5: 3D (left) and 2D (right) views of molecular interactions of a 3CLpro-caryophyllene oxide. b 3CLpro-Remdesivir. c ACE2-bisabolene. d ACE2-Remdesivir. e NSP3-caryophyllene oxide. f NSP3-Remdesivir. $\mathbf{g}$ NSP9-caryophyllene oxide. $\mathbf{h}$ NSP9-Remdesivir. i RDRP-cryophyllene oxide. $\mathbf{j}$ RDRP-Remdesivir. $\mathbf{k}$ RP1A-bergamotene. I RP1A-Remdesivir complexes 


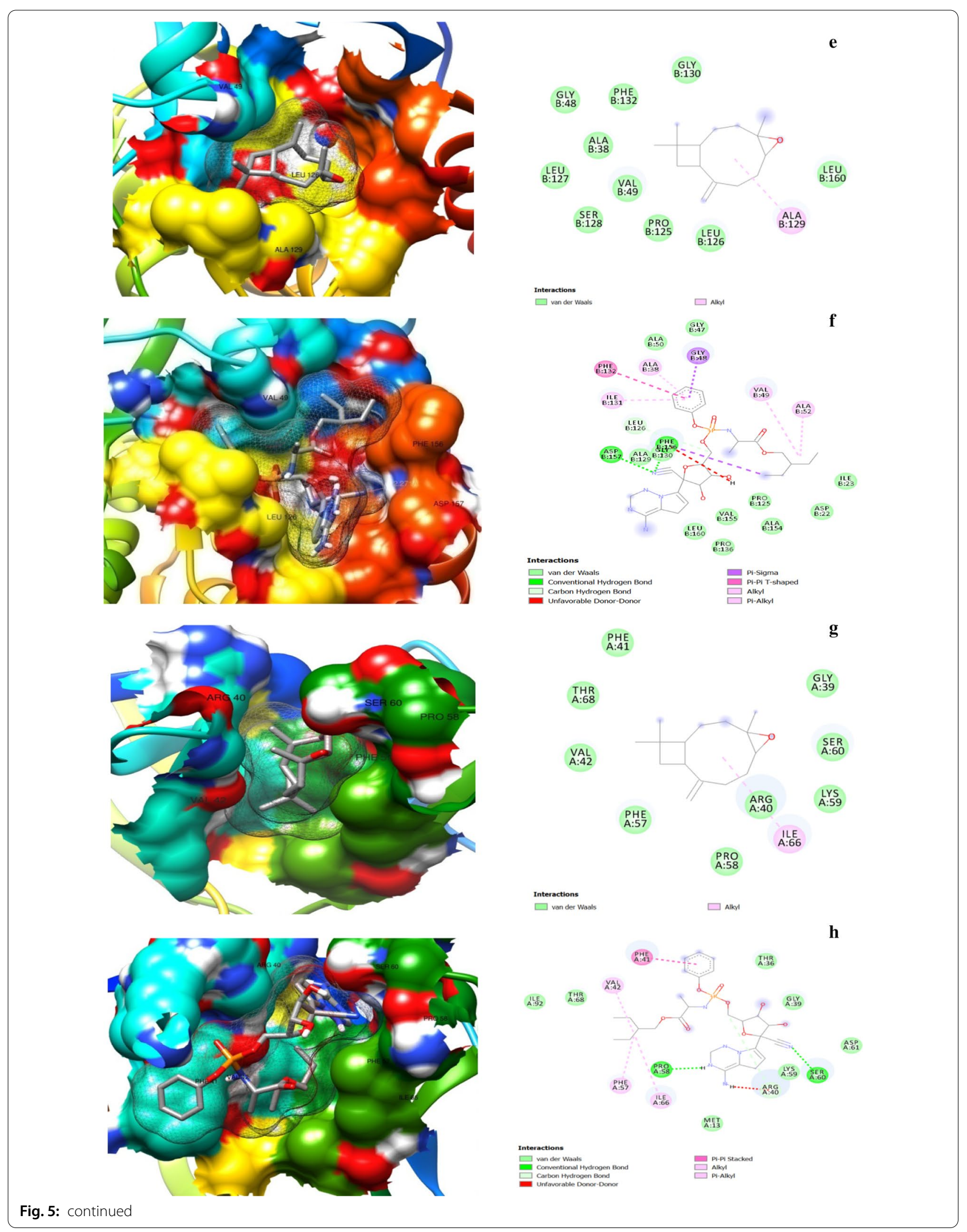




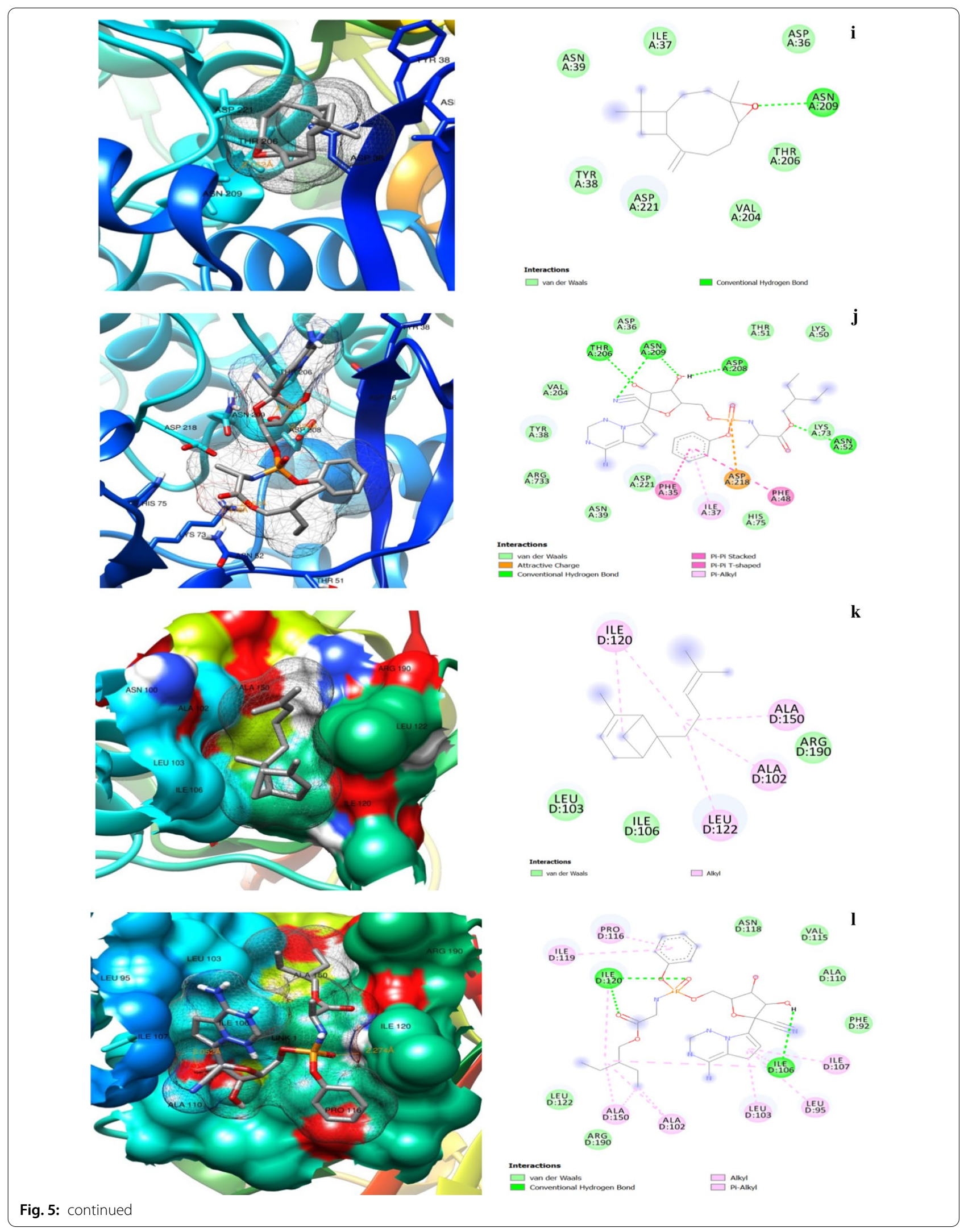


Table 4 Protein residue interactions with the compounds and Remdesivir

\begin{tabular}{|c|c|c|c|c|c|c|c|}
\hline \multirow{2}{*}{$\begin{array}{l}\text { Protein-ligand } \\
\text { complex }\end{array}$} & \multicolumn{7}{|c|}{ Interacting residues } \\
\hline & Hydrogen bond & $\begin{array}{l}\text { Unfavorable } \\
\text { donor-donor }\end{array}$ & Pi-sigma & Pi-alkyl & Alkyl & $\begin{array}{l}\text { Carbon- } \\
\text { hydrogen }\end{array}$ & Attractive charge \\
\hline $\begin{array}{l}\text { 3CLpro-Cary- } \\
\text { opyellene oxide }\end{array}$ & - & - & PHE294 & - & - & - & - \\
\hline $\begin{array}{l}\text { 3CLpro-Remde- } \\
\text { sivir }\end{array}$ & SER158;THR111 & SER158;THR292 & - & - & 1LE249; PRO293 & - & - \\
\hline $\begin{array}{l}\text { ACE2- } \\
\beta \text {-bisabolene }\end{array}$ & - & - & - & $\begin{array}{l}\text { HIS450; LYS541; } \\
\text { LYS441 }\end{array}$ & $\begin{array}{l}\text { HIS540; PRO415; } \\
\text { PHE438; ILE291 }\end{array}$ & - & - \\
\hline ACE2-Remdesivir & $\begin{array}{l}\text { GLU398; ALA348; } \\
\text { ASP350 }\end{array}$ & - & TRP349 & TRP349; ARG393 & - & $\begin{array}{l}\text { GLU402; ALA348; } \\
\text { ASP382 }\end{array}$ & ASP382; ASP350 \\
\hline $\begin{array}{l}\text { NSP3-Cryophyl- } \\
\text { lene oxide }\end{array}$ & - & - & - & - & ALA129 & - & - \\
\hline NSP3-Remdesivir & ASP157; PHE156 & PHE156 & GLY48; PHE156 & ALA38; ILE131 & VAL49; ALA52 & LEU126 & - \\
\hline $\begin{array}{l}\text { NSP9-Cryophyl- } \\
\text { lene oxide }\end{array}$ & - & - & - & - & ILE68 & - & - \\
\hline NSP9-Remdesivir & PRO58; SER60 & ARG40 & - & VAL42; PHE56 & ILE66 & ARG40 & - \\
\hline $\begin{array}{l}\text { RDRP-Cryophyl- } \\
\text { lene oxide }\end{array}$ & ASN209 & - & - & - & - & - & - \\
\hline RDRP-Remdesivir & $\begin{array}{l}\text { ASN52; THR206; } \\
\text { ASN209; } \\
\text { ASP208 }\end{array}$ & - & - & ILE37 & - & - & ASP218 \\
\hline $\begin{array}{l}\text { RP1A- } \\
\text { a-bergamotene }\end{array}$ & - & - & - & - & $\begin{array}{l}\text { ILE120; ALA150; } \\
\text { ALA102; } \\
\text { LEU122 }\end{array}$ & - & - \\
\hline RP1A-Remdesivir & ILE120; ILE106 & - & - & $\begin{array}{l}\text { PRO116; ILE119; } \\
\text { ILE107; LEU95; } \\
\text { LEU103 }\end{array}$ & $\begin{array}{l}\text { ILE120; ILE106; } \\
\text { ALA150; } \\
\text { ALA102 }\end{array}$ & - & - \\
\hline
\end{tabular}

GC-MS analysis of the oil showed that it contained many compounds with known biological and therapeutic activities. The docking studies of these compounds against some major targets on the SARS-CoV-2 revealed that caryophyllene oxide, $\alpha$-bergamotene, and $\beta$-bisabolene were promising candidates in the inhibition of the activity of these proteins. Their ADMET results further indicated that they would have good pharmacological and pharmacodynamic properties in the human system. There is therefore need for further in vitro, in vivo, and clinical trials to validate the potentials of these compounds in the eradication of the coronavirus pandemic.

\section{Abbreviations}

COVID-19: Coronavirus disease 2019; SARS-CoV-2: Severe acute respiratory syndrome coronavirus 2; GC-MS: Gas chromatography-mass spectrometer; MSD: Mass selective detector; NIST: National Institute of Standards and Technology; RP1A: Replicase polyprotein; NSP9: Nonstructural protein 9; NSP3: Nonstructural protein 3; 3CLpro: 3-Chymotrypsin-like protease; RDRP: RNAdependent RNA polymerase; ACE2: Angiotensin-converting enzyme; CASTp: Computed atlas for surface topography of proteins; ADMET: Absorption, distribution, metabolism and elimination and toxicity; FDA: Food and drug administration; TYR: Tyrosine; MET: Methionine; TRP: Tryptophan; ILE: Isoleusine; SER: Serine; ALA: Alanine; PHE: Phenylalanine; THR: Threonine; VAL: Valine; ARG: Arginine; PRO: Proline; LEU: Leucine; HIS: Histidine; ASN: Asparagine; GLY: Glycine; LYS: Lysine; GLU: Glutathione.

\section{Acknowledgements}

The authors are grateful to ChemSolvers Research and Computational Laboratory Studio, Owerri, Nigeria, for assisting in the in silico study.

\section{Authors' contributions}

CED conceived, designed, and wrote the research, and performed the DFT studies. IAD extracted and characterized the oil sample, and proof-read the manuscript. AEA performed the docking studies and post docking analysis. All authors have approved the manuscript in the present form and gave the permission to submit the manuscript for publication. All authors read and approved the final manuscript.

\section{Funding}

No funds, grants, or other support was received.

\section{Availability of data and materials}

All data generated or analyzed during this study are included in this published article.

\section{Declarations}

Ethics approval and consent to participate

Not applicable.

\section{Consent for publication}

Not applicable.

\section{Competing interests}

The authors declare that they have no competing interests. 


\section{Author details}

1 Surface Chemistry and Environmental Technology (SCENT) Research Unit, Department of Chemistry, Imo State University, Owerri, Imo State, Nigeria. 2 Department of Chemistry, Federal University of Technology, Owerri, Imo State, Nigeria. ${ }^{3}$ Department of Biochemistry, Faculty of Medical Sciences, University of Jos, Jos, Plateau State, Nigeria. ${ }^{4}$ Africa Center of Excellence in Phytomedicine Research and Development, University of Jos, Jos, Plateau State, Nigeria.

Received: 28 January 2021 Accepted: 28 February 2021

Published online: 12 March 2021

\section{References}

Abdelmeguid NE, Fakhoury R, Kamal SM, Al Wafai RJ (2010) Effects of Nigella sativa and thymoquinone on biochemical and subcellular changes in pancreatic $\beta$-cells of streptozotocin-induced diabetic rats. J Diabetes 2(4):256-266

Adeoye-Isijola MO, Olajuyigbe OO, Jonathan SG, Coopoosamy RM (2018) Bioactive compounds in ethanol extract of Lentinus squarrosulus mont - a Nigerian medicinal macrofungus. Afr J Tradit Complement Altern Med 15(2):42-50

Ahmad A, Husain A, Mujeeb M, Khan SA, Najmi AK, Siddique NA et al (2013) A review on therapeutic potential of Nigella sativa: A miracle herb. Asian Pac J Trop Biomed 3(5):337-352

AI YM (1986) Phytochemical studies of the plants used in traditional medicine of Saudi Arabia. Fitoterapia 57:179-182

Awadalla EA (2012) Ameliorative effect of the crude oil of the Nigella sativa on oxidative stress induced in rat testes by cisplatin treatment. Biomed Prev Nutr 2:265-268

Balamurugan M, Selvam GG, Thinakaran T, Sivakumar K. Biochemical study and GC-MS analysis of Hypnea musciformis (Wulf.) Lamouroux Am-Euras. J Sci Res. 2013; 8(3):117-123.

Begum IF, Mohankumar R, Jeevan M, Ramani K (2016) GC-MS analysis of bioactive molecules derived from Paracoccus pantotrophus FMR19 and the antimicrobial activity against bacterial pathogens and MDROs. Indian J Microbiol 56:426-432

BIOVIA, Dassault Systemes, San Diego, Discovery studio modeling environment, 2020.

Caboni P, Ntalli NG, Aissani N, Cavoski I, Angioni A (2012) Nematicidal activity of ( $E, E)$-2,4-decadienal and (E)-2-decenal from Ailanthus altissima against Meloidogyne javanica. J Agric Food Chem 60(4):1146-1151

Chavan M, Wakte P, Shinde D (2010) Analgesic and anti-inflammatory activity of cryophyllene oxide from Annona squamosa leaf bark. Phytomedicine 17(2):149-151

Datta AK, Saha A, Bhattacharya A, Mandal A, Paul R Sonali SS. Black cumin (Nigella sativa L.) - A review. J Plant Dev Sci. 2012; 4(1):1-43.

Duru CE (2020) Mineral and phytochemical evaluation of Zea mays husk. Sci Afr 7:e00224. https://doi.org/10.1016/j.sciaf.2019.e00224

Duru CE, Duru IA, Bilar A (2020) Computational investigation of sugar fermentation inhibition by bergenin at the pyruvate decarboxylate isoenzyme 1 target of Scharomyces cervisiae. J Med Plants Stud 8(6):21-25

Duru IA, Duru CE (2020) Molecular docking of compounds in the essential oil of Ocimium gratissimum leaf against PIM-1 kinase of Escherichia coli. Ej-Chem 1(6):1-4

El-Sawi SA, Maamoun AA, Salama AH, Farghaly AA (2020) Chemical profiling of Thevetia peruviana leaves cytotoxic active extracts enhanced by microemulsion formulation. Bull Natl Res Cent 44:93. https://doi.org/10.1186/ s42269-020-00339-3

Engel G, Brinkmann J (2017) Nigella- Nigella sativa, Ranunculaceae. HerbalGram 114:8-16

Gao Y, Yan L, Huang Y, Liu F, Zhao Y, Cao L et al (2020) Structure of the RNA-dependent RNA polymerase from COVID-19 virus. Science 368(6492):779-782

Guy JL, Jackson RM, Jensen HA, Hooper NM, Turner AJ (2005) Identification of critical active-site residues in angiotensin-converting enzyme-2 (ACE2) by site-directed mutagenesis. FEBS J 272(14):3512-3520

Hadi MY, Mohammed GJ, Hameed IH (2016) Analysis of bioactive chemical compounds of Nigella sativa using gas chromatography-mass spectrometry. J Pharmacognosy Phytother 8(2):8-24 http://sts.bioe.uic.edu/castp/index.html?j_5f45dd381f58d

Jin Z, Du X, Xu Y, Deng Y, Liu M, Zhao Y et al (2020) Structure of $M^{\text {pro from }}$ SARS-CoV-2 and discovery of its inhibitors. Nature 582(7811):289-293

Johnson TO, Odoh KD, Akinanmi AO, Adegboyega AE (2020) Biochemical evaluation and molecular docking assessment of the anti-inflammatory potential of Phyllanthus nivosus leaf against ulcerative colitis. Heliyon 6:e03893. https://doi.org/10.1016/j.heliyon.2020.e03893

Kamil ZH (2013) Spectacular black seeds (Nigella sativa): Medical importance review. Med J Babylon 10(4):1-9

Konkolova E, Klima M, Nencka R, Boura E (2020) Structural analysis of the putative SARS-CoV-2 primase complex. J Struct Biol 211(2):107548. https://doi. org/10.1016/j.jsb.2020.107548

Kumar Y, Singh H, Patel CN (2020). In silico prediction of potential inhibitors for the Main protease of SARS-CoV-2 using molecular docking and dynamics simulation based drug-repurposing. J Infect Public Health. 2020; 13(9):1210-1223.

Lang G, Buchbauer G (2012) A review on recent research results (2008-2010) on essential oils as antimicrobials and antifungals. A review Flavour Fragr J 27(1):13-39

Lipinski CA (2016) Rule of five in 2015 and beyond: Target and ligand structural limitations, ligand chemistry structure and drug discovery project decisions. Adv Drug Deliv Rev 101:34-41

Marques FM, Figueira MM, Schmitt EFP, Kondratyuk TP, Endringer DC, Scherer R et al (2019) In vitro anti-inflammatory activity of terpenes via suppression of superoxide and nitric oxide generation and the NF-KB signalling pathway. Inflammopharmacology 27(2):281-289

Michalska K, Kim Y, Jedrzejczak R, Maltseva NI, Stols L, Endres M, Joachimiak A (2020) Crystal structures of SARS-CoV-2 ADP-ribose phosphatase: from the apo form to ligand complexes. IUCrJ 7(Pt 5):814-824

Muniyan R, Gurunathan J (2016) Lauric acid and myristic acid from Allium sativum inhibit the growth of Mycobacterium tuberculosis H37Ra: in silico analysis reveals possible binding to protein kinase B. Pharm Biol 54(12):2814-2821

Naz H (2011) Nigella sativa: the miraculous herb. Pak J Biochem Mol Biol 44:44-48

Peng L, Liu A, Shen Y, Xu H, Yang S, Ying X et al (2013) Antitumor and antiangiogenesis effects of thymoquinone on osteosarcoma through the NF-kB pathway. Oncol Rep 29(2):571-578

Pettersen EF, Goddard TD, Huang CC, Couch GS, Greenblatt DM, Meng EC, Ferrin TE (2004) UCSF Chimera- a visualization system for exploratory research and analysis. J Comput Chem 25(13):1605-1612

Punch Newspaper, April 7, 2020. https://healthwise.punchng.com/i-fough t-covid-19-with-vitamin-c-black-seed-oil-mixed-with-honey-gov-makin de-2/

Saeed NM, El-Demerdash E, Abdel-Rahman HM, Algandaby MM, Al-Abbasi FA, Abdel-Naim AB. Anti-inflammatory activity of methyl palmitate and ethyl palmitate in different experimental rat models. Toxicol Appl Pharmacol. 2012; 1:264(1):84-93.

Shariq IM, Israil AM, Iqbal A, Brijesh P. Morpho-physiological characterization of seeds and seedlings of Nigella sativa Linn.: Study on Indian germplasm. Int Res J Biol Sci. 2015; 4(4):38-42.

Sharma N, Ahirwar D, Jhade D, Gupta S (2009) Medicinal and phamacological potential of Nigella sativa: A review. Ethnobot Rev 13:946-955

Sultan MT, Butt MS, Karim R, lqbal SZ, Ahmad S, Zia-UI-Haq M et al (2014) Effect of Nigella sativa fixed and essential oils on antioxidant status, hepatic enzymes, and immunity in streptozotocin induced diabetes mellitus. BMC Complement Altern Med 14:193. https://doi. org/10.1186/1472-6882-14-193

Tan K, Kim Y, Jedrzejczak R, Maltseva N, Endres M, Michalska K, Joachimiak A. The crystal structure of Nsp9 RNA binding protein of SARS CoV-2. Center for Structural Genomics of Infectious Diseases (CSGID); 2020. https://doi. org/https://doi.org/10.2210/pdb6W4B/pdb

Tian W, Chen C, Lei X, Zhao J, Liang J. CASTp 3.0: computed atlas of surface topography of proteins. Nucleic Acids Res. 2018; 46:363-367.

Tsao YC, Chang YJ, Wang CH, Chen L (2020) Discovery of isoplumbagin as a novel NQO1 substrate and anti-cancer quinone. Int J Mol Sci 21(12):4378. https://doi.org/10.3390/ijms21124378

Umar S, Zargan J, Umar K, Ahmad S, Katiyar CK, Khan HA (2012) Modulation of the oxidative stress and inflammatory cytokine response by thymoquinone in the collagen induced arthritis in Wistar rats. Chem Biol Interact 197(1):40-46 
Vavilov NI, Dorofeev VF (1992) Origin and Geography of Cultivated Plants. Cambridge University Press, Cambridge, UK

Wang Q, Zhang Y, Wu L, Niu S, Song C, Zhang Z et al (2020) Structural and functional basis of SARS-CoV-2 entry by using human ACE2. Cell 181(4):894-904

WHO. Novel coronavirus (2019-nCoV), 2020. https://www.euro.who.int/en/ health-topics/health-emergencies/novel-coronavirus-2019-ncov_old.

Williamson BN, Feldmann F, Schwarz B, Meade-White K, Porter DP, Schulz J et al (2020) Clinical benefit of remdesivir in rhesus macaques infected with SARS-CoV-2. Nature 585(7824):273-276

Wu JHY, Marklund M, Imamura F, Tintle N, Ardisson Korat AV, de Goede J et al (2017) Omega- 6 fatty acid biomarkers and incident type 2 diabetes: pooled analysis of individual-level data for 39740 adults from 20 prospective cohort studies. Lancet Diabetes Endocrinol 5(12):965-974

Yang H, Lou C, Sun L, Li J, Cai Y, Wang Z, et al. admetSAR 2.0: Wed-service for prediction and optimization of chemical ADMET properties. Bioinformatics (Oxford, England), 2019; 35(6):1067-1069.
Yimer EM, Tuem KB, Karim A, Ur-Rehman N, Anwar F. Nigella sativa L. (Black Cumin): A promising natural remedy for wide range of illnesses. Evid Based Complement Alternat Med. 2019; 1528635. https://doi. org/10.1155/2019/1528635

Zhao Z, Vavrusova M, Skibsted LH (2018) Antioxidant activity and calcium binding of isomeric hydroxybenzoates. J Food Drug Anal 26(2):591-598

Zhong HA (2017) ADMET properties: overview and current topics. In: Grover A (ed) Drug design: principles and applications. Springer, Singapore, pp 113-133

\section{Publisher's Note}

Springer Nature remains neutral with regard to jurisdictional claims in published maps and institutional affiliations.

\section{Submit your manuscript to a SpringerOpen ${ }^{\circ}$ journal and benefit from:}

- Convenient online submission

- Rigorous peer review

- Open access: articles freely available online

- High visibility within the field

- Retaining the copyright to your article

Submit your next manuscript at $\gg$ springeropen.com 